\title{
A cross-sectional analysis of physics self-efficacy, perceived recognition, interest and identity of physics majors
}

\author{
Alexandru Maries \\ Department of Physics, University of Cincinnati, 2600 Clifton Ave, Cincinnati, OH, 45221
}

Kyle Whitcomb

Department of Physics and Astronomy, University of Pittsburgh, 3941 O'Hara St., Pittsburgh, PA, 15260

Chandralekha Singh

Department of Physics and Astronomy, University of Pittsburgh, 3941 O'Hara St., Pittsburgh, PA, 15260

\begin{abstract}
The importance of motivational characteristics in physics education has been increasingly recognized in recent years, with prior studies establishing a framework for how students' identity as a physics person is composed of their perceived recognition by physics instructors and peers, along with their physics self-efficacy and interest. We seek to extend this research beyond introductory physics students by using five years of crosssectional data collected from motivational surveys administered to physics majors throughout their undergraduate education and to the first-year physics Ph.D. students at a large research university in the US. We find that physics majors in the first year tend to respond to the motivational survey prompts more positively than their non-physics major peers, though with a smaller mean difference in self-efficacy than in the other motivational beliefs. Further, on average, the responses of physics majors over time from their first year of the undergraduate curriculum through the first year of graduate school remain largely consistent, indicating that students are constantly adjusting their interpretation of the survey items to match the current level of expertise in physics courses they are taking. Finally, consistent with prior studies with introductory physics students, we find that perceived recognition is the best predictor of physics identity for physics majors throughout their entire education in physics, pointing to the importance of physics instructors making a concerted effort to constantly recognize their students throughout as people who can excel in physics.
\end{abstract}

\footnotetext{
2021 PERC Proceedings edited by Bennett, Frank, and Vieyra; Peer-reviewed, doi.org/10.1119/perc.2021.pr.Maries Published by the American Association of Physics Teachers under a Creative Commons Attribution 4.0 license. Further distribution must maintain the cover page and attribution to the article's authors.
} 


\section{INTRODUCTION AND FRAMEWORK}

In recent years, education researchers have been increasingly recognizing the importance of attending to students' motivational characteristics in STEM domains to improve the positive impact on learning achieved by research-based instructional strategies [1-4]. Physics motivational characteristics include, among others, students' self-efficacy, perceived recognition by others such as instructors and teaching assistants, interest, and physics identity. Prior research has shown that when instruction explicitly addresses some of these motivational beliefs, student learning is improved and achievement gaps reduced [2]. Moreover, researchers have called for additional research into what they termed the "heads-and-hearts" hypothesis [1], which suggests that instruction is more likely to remove achievement gaps when incorporating two key elements: effective pedagogy and use of inclusive teaching practices that attend to students' motivational characteristics.

Prior research has also linked some of these motivational characteristics to students' physics identity [5-9], which can play a major role in the academic trajectory and future career choices of undergraduates [10-13]. Researchers have [5-9] proposed a framework which suggests that students' physics identity is informed by three motivational characteristics: (1) perceived recognition by instructors, TAs, peers, and family, etc. (or "external identity"); (2) physics competency belief (closely tied to self-efficacy); and (3) interest in physics. Prior studies have found that perceived recognition is the strongest predictor of physics identity, which implies that physics instructors can boost their students' identification as a physics person by making an effort to recognize students as people who can excel in physics [5-9]. Self-efficacy, defined by Bandura as one's belief in one's ability to succeed at a particular task or subject [14], is another extremely important motivational belief in this framework. Many prior studies related to self-efficacy have shown that it is linked to many aspects of education, both in general and in physics specifically, including academic achievement, persistence in the major, and career choices after graduation [3,4,9-17].

In order to extend the prior research on students' physics motivational characteristics, which has primarily focused almost exclusively on either high-school or introductory students, and in one case on first-year and senior women in physics [2-12,16-24], here we focus on the physics motivational characteristics that have been linked to students' physics identity (perceived recognition, interest, and self-efficacy) for undergraduate physics majors across different years and first-year graduate students at a large research university in the US. Our research questions to guide this investigation are as follows:

RQ1. What are the trends over time for physics majors' physics perceived recognition, interest, self-efficacy, and identity as a physics person?

RQ2. How do the responses differ for physics majors and non-majors in the same first-year courses?

RQ3. How do the motivational beliefs of physics majors throughout their undergraduate education compare to the first-year physics graduate students at the same university?

\section{METHODOLOGY}

The university at which this study was conducted is a public, doctoral university, with a large, primarily residential undergraduate population that is full-time and reasonably selective with low transfer-in from other schools. A validated motivational survey was administered during the first and last two weeks of the semester in lecture courses throughout the undergraduate physics curriculum as well as first-year graduate courses.

In previous studies, the motivational survey was validated for calculus-based introductory physics courses, in which the majority of students are non-physics majors (engineering, chemistry and math majors in addition to physics majors) [7-9,16,19]. Since our study is focused on physics majors, we validated the survey via 15 think-aloud interviews with physics majors across different years and 5 graduate students who answered each survey question while thinking-aloud and later clarified why they responded in a certain manner when the interviewer asked for elaborations. These 20 interviews confirmed that these students were correctly interpreting the survey items. Next, we conducted an exploratory factor analysis and found that the items group into the constructs labeled in Table I in a manner very similar to the previous studies involving mainly non-majors. A follow-up confirmatory factor analysis (CFA) found that the specified factors have "good" model fit (SRMR $<0.07$, CFI $>0.90, \mathrm{TL}>0.90)$. The standardized factor loadings $(\lambda)$ from this CFA are reported for each item in Table I, where $\lambda^{2}$ indicates the amount of variance explained in each item by the factors. Finally, we also report Cronbach's $\alpha$ in Table I for each factor with multiple items.

The survey takes approximately 10 minutes for students to complete. Since we are interested in the motivational characteristics of physics majors, we used de-identified data provided by the university via an honest broker to determine which students were physics majors.

The survey items from the validated motivational survey pertaining to this study are shown in Table I along with selected validation measures for the responses of physics majors (see next paragraph). Students responded to each item with the degree to which they agreed or disagreed with the statements on a Likert scale from 1-4, with the exception of the first two items for "Interest", which had unique response options listed in the caption of Table 1. Consistent with prior research on identity, we used only one question pertaining to students' physics identity [5-9], but multiple questions for other factors.

We will refer to the survey administered in the first two weeks of the semester as the "pre survey" and the survey 
Table I. The survey items used in this study along with the response options given to students. The items are grouped into sets based upon the results of the factor analysis, and the associated motivational construct for each set of items is listed. For each construct with multiple items, Cronbach's $\alpha$ is provided as a measure of the coherence (internal consistency) of these items. For each item, the standardized factor loading $\lambda$ from a CFA model is listed. In the CFA, the physics identity item loaded on each of the other three constructs and so three $\lambda$ values are specified for each of the interest $\left(\lambda_{\text {Int }}\right)$, perceived recognition $\left(\lambda_{\text {Rec }}\right)$, and self-efficacy $\left(\lambda_{\mathrm{SE}}\right)$ factors. All items are on a Likert scale from 1 to 4 measuring the degree to which students agree with the statements (with 1 indicating strong disagreement and 4 indicating strong agreement), except the first two Interest items which have the following unique response options. Option set $A=\{$ Never, Once a week, Once a month, Every day $\}$. Option set B $=$ \{Very boring, Boring, Interesting, Very interesting $\}$. Items marked with a $\uparrow$ are reverse-coded prior to analysis in order to align the scales of all items.

\begin{tabular}{|c|c|c|c|}
\hline $\begin{array}{l}\text { Motivational } \\
\text { construct }\end{array}$ & $\alpha$ & $\bar{\lambda} \lambda$ & Q Question text \\
\hline \multirow{5}{*}{ Interest } & \multirow{5}{*}{0.82} & 0.52 & I wonder about how physics works [option set A] \\
\hline & & 0.69 & In general, I find physics [option set B] \\
\hline & & 0.73 & I want to know everything I can about physics \\
\hline & & 0.76 & I am curious about recent discoveries in physics \\
\hline & & 0.82 & I want to know about the current research that physicists are doing \\
\hline \multirow{3}{*}{$\begin{array}{l}\text { Perceived } \\
\text { Recognition }\end{array}$} & \multirow{3}{*}{0.79} & 0.90 & My family sees me as a physics person \\
\hline & & 0.90 & My friends see me as a physics person \\
\hline & & 0.58 & My physics instructor/TA sees me as a physics person \\
\hline \multirow{7}{*}{$\begin{array}{l}\text { Self- } \\
\text { Efficacy }\end{array}$} & \multirow{7}{*}{0.82} & 0.56 & Other people understand more than I do about what is going on in this physics course \\
\hline & & 0.65 & I am able to help my classmates with physics in the laboratory or in recitation \\
\hline & & 0.68 & ${ }^{\dagger}$ I get a sinking feeling when I think of trying to tackle tough physics problems \\
\hline & & 0.70 & I understand concepts I have studied in physics \\
\hline & & 0.68 & If I wanted to, I could be good at physics research \\
\hline & & 0.78 & If I study, I will do well on a physics test \\
\hline & & 0.73 & If I encounter a setback in a physics exam, I can overcome it \\
\hline $\begin{array}{l}\text { Physics } \\
\text { Identity }\end{array}$ & N/A & $\begin{array}{c}\lambda_{\text {Int }}=0.24 \\
\lambda_{\text {Rec }}=0.27 \\
\lambda_{\mathrm{SE}}=0.46\end{array}$ & I see myself as a physics person \\
\hline
\end{tabular}

administered in the final two weeks as the "post survey." Further, survey responses were grouped into "years" corresponding to the typical timeline of physics courses for students at the studied university. For example, responses from introductory physics 1 students are categorized as "year 1" while responses from quantum mechanics students are categorized as "year 4." Students take introductory physics in year 1 and modern physics in year 2 (along with three of the five mandatory mathematics courses beyond calculus- 1 and calculus-2, which they take in year 1). A majority of physics courses for the majors (classical mechanics (CM), electricity and magnetism (EM), thermal physics beyond introductory level and quantum physics) are taken in the third and fourth years. The sample size varies from year to year and in some cases differs between motivational constructs as items relating to physics identity and perceived recognition were added in Fall 2017. We note that in our cross-sectional analysis, some undergraduate students may be included in multiple courses in the data but the undergraduate and graduate student cohorts, though at the same university, are entirely separate. We report the exact sample size for each analysis in Results.

In order to investigate trends over time and answer RQ1, $\mathbf{R Q 2}$ and RQ3, we restricted the sample to matched pre and post responses (i.e., only those students who responded to both the pre and post survey items). Descriptive statistics (sample size, mean, and standard error) were calculated on these matched responses [25]. Then, in order to test the framework for physics identity, we tested multiple linear regression models [26] on only the post survey responses from students in each year, as has been done in previous studies with this framework [5-9]. Since pre survey responses do not appear in the models, we did not restrict to the matched responses in these multiple linear regression models, instead using all available post survey responses (although we find that the results are qualitatively similar using post survey responses with matched data only).

\section{RESULTS}

In order to answer RQ1 and investigate the trends of physics majors' identity, perceived recognition, selfefficacy, and interest over time, we calculated the mean and standard error of each construct for physics majors in each year and plotted them over time in Fig. 1. We observe that for physics majors, all four constructs remain remarkably consistent throughout the physics majors' studies and are comparable to those for graduate students. In particular, perceived recognition (Fig. 1b) and interest (Fig. 1c) show very little change even from the earliest time point (Year 1 pre) to the latest (Grad post). Perceived recognition ranges from a minimum of 3.24 in Year 2 post to a maximum of 3.40 in Year 4 pre, while interest ranges from a minimum of 3.45 in Year 4 post to a maximum of 3.73 in Year 1 post. 

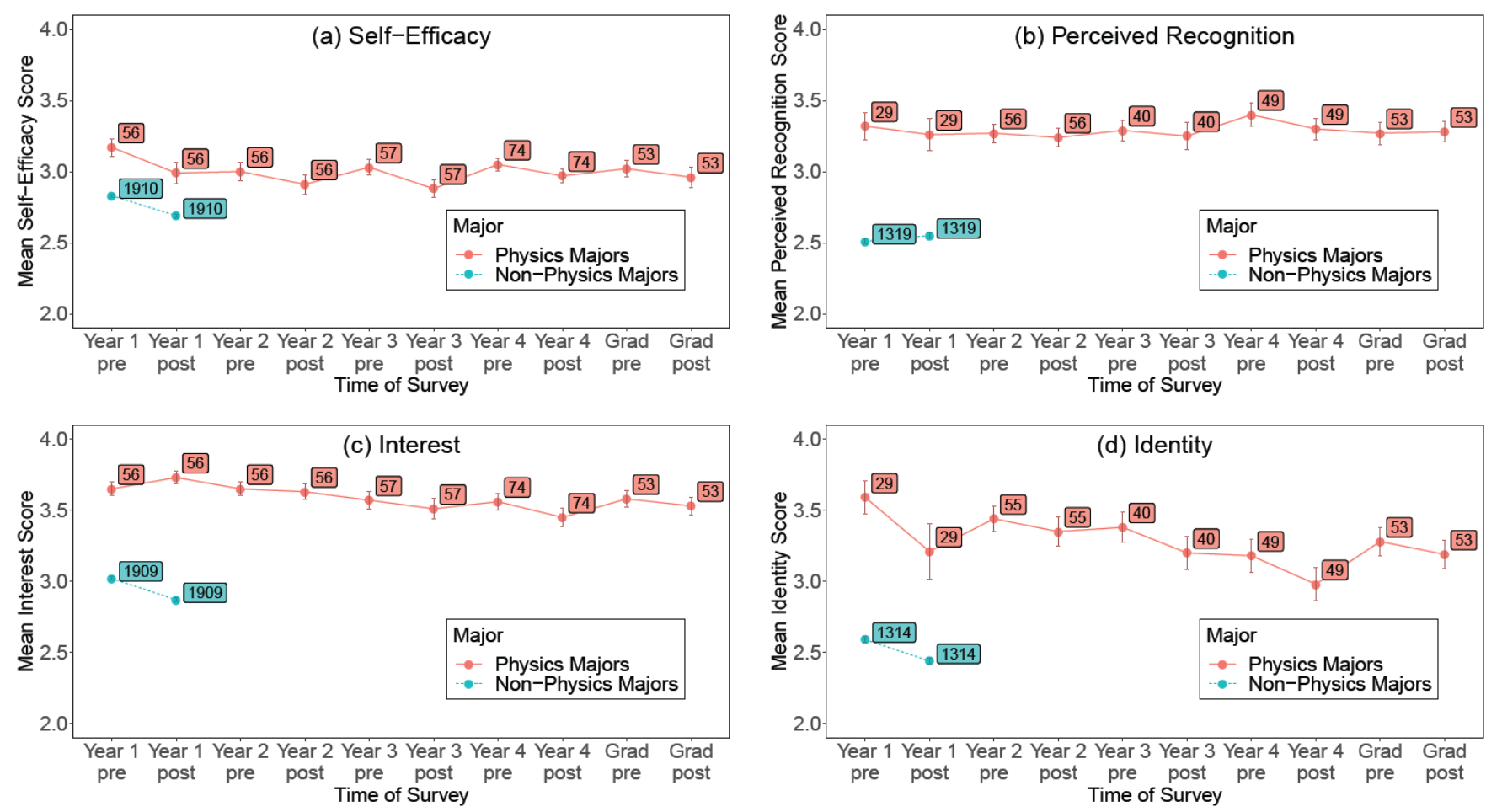

FIG. 1. The mean scores on (a) self-efficacy, (b) perceived recognition, (c) interest, and (d) identity are plotted along with their standard error (note that the vertical axis is limited to $2-4$ but the Likert scale was from 1-4). The mean scores are plotted separately for the matched pre and post survey responses of physics majors in each of the four undergraduate years as well as first-year non-physics majors and first-year physics graduate students ("Grad"). The sample size is reported next to each point. Lines connecting points are drawn as guides to the eye.

Self-efficacy (Fig. 1a) shows a slight drop from Year 1 pre pre (at 3.17) to Year 1 post, but after that point it remains relatively consistent through Grad post, with slight decreases from each pre survey to the following post survey followed by a slight increase in the next year's pre survey. Overall, the maximum self-efficacy for physics majors occurs in Year 1 pre at 3.17 and the minimum in Year 3 post at 2.88. Students' physics identity (Fig. 1d), while still largely consistent over time, shows a slight decline from the maximum 3.59 in Year 1 pre to the minimum 2.98 in Year 4 post (i.e., the span of undergraduate years). This trend is reversed for graduate students whose mean physics identity score rises slightly relative to Year 4 post undergraduate values. Note that graduate students comprise a different cohort than the undergraduate students.

We now compare majors to non-majors in Year 1 to answer RQ2. The two sets of responses that appear for Year 1 pre and Year 1 post are from the same physics courses, with those students who were identified as physics majors separated from the remaining non-physics majors. We find that on all measures, physics majors respond more positively on average than their non-physics major peers, though the difference between the two means is smaller in self-efficacy than in the other three constructs. In particular, for physics identity (Fig. 1d), the difference is 1.00 in pre and 0.77 in post; for physics perceived recognition (Fig. 1b) the difference is 0.81 in pre and 0.71 in post; and for interest (Fig. 1c) the difference is 0.63 in pre and 0.86 in post.
However, majors and non-majors respond much more similarly in physics self-efficacy measures, with majors only 0.34 and 0.30 higher on average in pre and post, respectively. Comparing physics majors and graduate students (RQ3), we observe that the two groups show very similar averages in self-efficacy, perceived recognition, and interest. The only difference, which is quite small, is in physics identity where Year 4 undergraduate students (post) and graduate students (pre) differ by roughly 0.25 . This might be at least partly due to the fact that some of the senior physics majors do not intend to pursue graduate school and their perception of themselves as a physics person may be lower than the others who pursued graduate school.

Turning next to the predictive relations, we use multiple linear regression models and test the model of physics identity predicted by interest, perceived recognition, and self-efficacy [5-9]. Table II shows six such models, one for physics majors in each year of study and one for non-majors in first-year physics courses. In every case, over $50 \%$ of the variance in physics identity is explained by the predictors (as indicated by $R^{2}$ in Table II).

The findings for non-majors in Year 1 shown in Table II reflect prior research for introductory physics including both majors and non-majors [5-9], and show that the primary predictor of physics identity is perceived recognition, while interest and self-efficacy are also statistically significant predictors (but smaller than perceived recognition). Focusing just on majors in Year 1, we find a somewhat 
Table II. Summary of findings from multiple regression models predicting physics identity from interest, perceived recognition, and selfefficacy among physics majors in each year of study and non-physics majors in the first year. Each column shows the results from a regression using data for the specified year. Reported are the standardized regression coefficients $(\beta)$ for each predictor along with the number of students $(N)$ and fraction of variance explained in physics identity $\left(R^{2}\right)$. The $p$-values are specified using asterisks, with non-significant predictors trimmed from the model and replaced by "-.".

\begin{tabular}{lcccccc}
\hline \hline Motivational & Year 1 & \multicolumn{5}{c}{ Standardized $\beta$ predicting physics identity } \\
Construct & Non-majors & Year 1 & Year 2 & Year 3 & Year 4 & Grad \\
\hline Interest & $0.25 * * *$ & - & - & $0.32 * * *$ & $0.31 * * *$ & - \\
Recognition & $0.48^{* * *}$ & $0.74 * * *$ & $0.45 * * *$ & $0.42 * * *$ & $0.48^{* * *}$ & $0.62 * * *$ \\
Self-Efficacy & $0.21 * * *$ & - & $0.35 * * *$ & $0.20 *$ & $0.22^{* *}$ & $0.34 * *$ \\
\hline$N$ & 2109 & 59 & 65 & 93 & 108 & 58 \\
$R^{2}$ & 0.64 & 0.54 & 0.52 & 0.63 & 0.63 & 0.74 \\
\hline
\end{tabular}

different model wherein perceived recognition is the sole predictor of physics identity. One hypothesis for this finding is that physics majors in their first year have more homogeneous levels of interest and self-efficacy in physics while there is more variation in their perceived recognition We note that there is also work to be done in improving student self-efficacy, as Fig. 1a shows that a full point improvement is possible on the 1-4 Likert scale.

Progressing to Year 2 (Table II), perceived recognition remains the top predictor of identity while self-efficacy becomes a statistically significant predictor. Following this, for physics majors in Years 3 and 4, interest becomes a significant predictor alongside perceived recognition and self-efficacy, with the standardized $\beta$ falling into a similar pattern to non-majors in Year 1. Finally, the model for graduate students shows that interest once again drops out as a significant predictor, leaving only perceived recognition and self-efficacy as the significant predictors of physics identity for graduate physics students. One hypothesis for this is that, as in the case with first year undergraduates, first year graduate students have a more homogeneous level of interest in physics while their perceived recognition and selfefficacy vary from student to student.

The main finding in these multiple regression models is that perceived recognition is universally the top predictor of physics identity. It is the only predictor of identity for physics majors during the first-year, with later years approaching a regression model resembling those found among a general population in introductory physics students in prior studies.

\section{SUMMARY AND IMPLICATIONS}

In this cross-sectional study, there are two main effects we observe (e.g., see Fig. 1). The first is that, by and large, physics majors from first-year undergraduate to first year graduate students respond to these items pertaining to physics perceived recognition, self-efficacy, interest and identity fairly consistently throughout their education. From the survey validation, we know that the students were correctly interpreting these items and these consistent responses over time indicate that students are constantly adjusting their perspective when responding to these items. For example, first-year physics students responding to the prompt "if I study, I will do well on a physics test" responded based on their belief about their performance on physics tests in their introductory physics course, while fourth-year physics students in a quantum mechanics course responded based on their belief about their performance on quantum mechanics tests (rather than how well they believe they could perform on tests from their earlier courses). The relative stability of these constructs for physics majors suggests that at each level, physics instructors should make explicit efforts to improve students' self-efficacy and interest by engaging in micro-affirmations and validation and recognizing students as people who can excel in physics.

The second major finding is the consistently higher responses of physics majors relative to their non-physics major peers in the same courses, which is not surprising. What might be surprising is that physics majors are more similar to their non-major peers in regards to self-efficacy (difference of around 0.3) than with regards to the other constructs (differences between 0.6-1.0).

The last major finding is that perceived recognition is consistently the top predictor of physics identity, and this is especially true for physics majors in their first year. These findings expand and strengthen the findings of previous studies using the Hazari et al. model [5-9], which called for physics instructors in introductory courses to make a concerted effort to recognize their students as people who can excel in physics. In particular, we find that recognition is even more important for physics majors in the first year than non-majors, and it consistently remains the top predictor for physics identity all the way through the first year in graduate school. Thus, we call upon all physics departments to implement measures to foster positive, encouraging interactions with all students to enhance their physics identity from introductory to graduate levels.

This study has focused on all students regardless of gender, race and ethnicity, etc. for physics majors and graduate students since the numbers of students were not large enough to make valid comparisons between subgroups of students. However, future research with more data could disaggregate the motivational constructs studied here by gender, race and ethnicity to investigate whether there are differences between different demographic groups for physics majors and non-majors, which could inform inclusive teaching practices in the physics curriculum. 
[1] E. J. Theobald, M. J. Hill, E. Tran, S. Agrawal, E. N. Arroyo, S. Behling, N. Chambwe, ... and S. Freeman, Active learning narrows achievement gaps for underrepresented students in undergraduate science, technology, engineering, and math, Proceedings of the National Academy of Sciences 117(12), 6476-6483 (2020).

[2] K. Binning, N. Kaufmann, E. McGreevy, O. Fotuhi, S. Chen, E. Marshman, Y. Z. Kalender, L. Limeri, L. Betancur, and C. Singh, Changing social norms to foster the benefits of collaboration in diverse workgroups, Psychological Science 31(9), 1-12 (2020).

[3] E. Marshman, Z. Y. Kalender, T. Nokes-Malach, C. Schunn, and C. Singh, Female students with A's have similar physics self-efficacy as male students with C's in introductory courses: A cause for alarm? Phys. Rev. Phys. Educ. Res. 14, 020123 (2018).

[4] M. Broda, J. Yun, B. Schneider, D. Yeager, G. Walton, and Matthew Diemer, Reducing inequality in academic success for incoming college students: A randomized trial of growth mindset and belonging interventions, J. Res. Educ. Effect. 11, 317 (2018).

[5] Z. Hazari, G. Sonnert, P. M. Sadler, and M.-C. Shanahan, Connecting high school physics experiences, outcome expectations, physics identity, and physics career choice: A gender study, J. Res. Sci. Teach. 47, 978 (2010), https://onlinelibrary.wiley.com/doi/pdf/10.1002/tea.20363.

[6] Z. Hazari, P. M. Sadler, and G. Sonnert, The science identity of college students: Exploring the intersection of gender, race, and ethnicity, J. Coll. Sci. Teach. 42, 82 (2013).

[7] Z. Y. Kalender, E. Marshman, C. D. Schunn, T. J. NokesMalach, and C. Singh, Gendered patterns in the construction of physics identity from motivational factors, Phys. Rev. Phys. Educ. Res. 15, 020119 (2019).

[8] Z. Y. Kalender, E. Marshman, C. D. Schunn, T. J. NokesMalach, and C. Singh, Why female science, technology, engineering, and mathematics majors do not identify with physics: They do not think others see them that way, Phys. Rev. Phys. Educ. Res. 15, 020148 (2019).

[9] Z. Y. Kalender, E. Marshman, C. D. Schunn, T. J. NokesMalach, and C. Singh, Damage caused by women's lower selfefficacy on physics learning, Phys. Rev. Phys. Educ. Res. 16, 010118 (2020).

[10] Z. Hazari, G. Potvin, R. M. Lock, F. Lung, G. Sonnert, and P. M. Sadler, Factors that affect the physical science career interest of female students: Testing five common hypotheses, Phys. Rev. ST Phys. Educ. Res. 9, 020115 (2013).

[11] R. M. Lock, Z. Hazari, and G. Potvin, Impact of out-of-class science and engineering activities on physics identity and career intentions, Phys. Rev. Phys. Educ. Res 15, 020137 (2019).

[12] A. T. Danielsson, Exploring woman university physics students 'doing gender' and 'doing physics', Gender and Education 24, 25 (2012), https://doi.org/10.1080/09540253.2011.565040.

[13] A. J. Gonsalves, Exploring how gender figures the identity trajectories of two doctoral students in observational astrophysics, Phys. Rev. Phys. Educ. Res. 14, 010146 (2018).

[14] A. Bandura, Social cognitive theory of self-regulation, Org. Behav. Hum. Dec. Proc. 50, 248 (1991).

[15] S. L. Beilock, R. J. Rydell, and A. R. McConnell, Stereotype threat and working memory: Mechanisms, alleviation, and spillover, J. Exp. Psych.: Gen. 136, 256 (2007).
[16] Z. Y. Kalender, E. Marshman, C. D. Schunn, T. J. NokesMalach, and C. Singh, Beliefs about competence: The story of self-efficacy, gender, and physics, in Diversity Across Disciplines: Research on People, Policy, Process and Paradigm, edited by A. Murrell, J. Petrie-Wyman, and A. Soudi (Information Age Publishing, 2020) pp. 3-18.

[17] R. M. Marra, K. A. Rodgers, D. Shen, and B. Bogue, Women engineering students and self-efficacy: A multi-year, multiinstitution study of women engineering student self-efficacy, J. Eng. Educ. 98, 27 (2009).

[18] Z. Hazari, D. Chari, G. Potvin, and E. Brewe, The context dependence of physics identity: Examining the role of performance/competence, recognition, interest, and sense of belonging for lower and upper female physics undergraduates, J. Res. Sci. Teach. 57(10), 1583-1607 (2020).

[19] E. Marshman, Z. Y. Kalender, C. Schunn, T. Nokes-Malach, and C. Singh, A longitudinal analysis of students' motivational characteristics in introductory physics courses: Gender differences, Can. J. Phys. 96, 391 (2017).

[20] J. M. Nissen and J. T. Shemwell, Gender, experience, and selfefficacy in introductory physics, Phys. Rev. Phys. Educ. Res. 12, 020105 (2016).

[21] B. Van Dusen and J. Nissen, Equity in college physics student learning: A critical quantitative intersectionality investigation, J. Res. Sci. Teach. 57, 33 (2020).

[22] V. Sawtelle, E. Brewe, and L. H. Kramer, Exploring the relationship between self-efficacy and retention in introductory physics, J. Res. Sci. Teach. 49, 1096 (2012).

[23] C. Monsalve, Z. Hazari, D. McPadden, G. Sonnert, and P. M. Sadler, Examining the relationship between career outcome expectations and physics identity, in Proceedings of the Physics Education Research Conference, Sacramento, CA (2016), p. 228.

[24] J. Blue, A. L. Traxler, and X. C. Cid, Gender matters, Physics Today 71, 40 (2018).

[25] D. Freedman, R. Pisani, and R. Purves, Statistics, 4th ed. (W. W. Norton \& Co., 2007).

[26] D. C. Montgomery, E. A. Peck, and G. G. Vining, Introduction to Linear Regression Analysis, 4th ed. (John Wiley \& Sons, 2012). 